\title{
Effectiveness of Transcutaneous Electrical Nerve Stimulation Therapy on whole Salivary Flow in Patients with Xerostomia and Healthy Adults
}

\author{
Satish Chhugani1 ${ }^{1}$, Gunjan Khatwani Chhugani1(1), Abhishek Sahu Vishwa Pratap ${ }^{1}{ }^{(1)}$, Lokesh

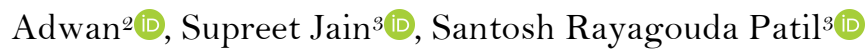

${ }^{1}$ Private Practice, Bilaspur, India.

${ }^{2}$ Department of Orthodontics, Rungta Dental College, Bhilai, India.

${ }^{3}$ Department of Oral Medicine and Radiology, New Horizon Dental College and Research Institute, Chhattisgarh, India.

Correspondence: Santosh R. Patil, Department of Oral Medicine and Radiology, New Horizon Dental College and Research Institute, Chhattisgarh, India. E-mail: drpsantosh@gmail.com

Academic Editor: Alidianne Fábia Cabral Cavalcanti

Received: 15 January 2021 / Review: 02 May 2021 / Accepted: 26 July 2021

\begin{abstract}
How to cite: Chhugani S, Chhugani GK, Pratap ASV, Adwan L, Jain S, Patil SR. Effectiveness of transcutaneous electrical nerve stimulation therapy on whole salivary flow in patients with xerostomia and healthy Adults. Pesqui Bras Odontopediatria Clín Integr. 2021; 21:e0008. https://doi.org/10.1590/pboci.2021.166
\end{abstract}

\begin{abstract}
Objective: To evaluate and compare the effectiveness of transcutaneous electrical nerve stimulation (TENS) therapy on whole salivary flow in patients with xerostomia and healthy adults. Material and Methods: Thirty subjects with a history of xerostomia and subjects with unstimulated salivary flow equal to or less than $0.5 \mathrm{ml}$ in $5 \mathrm{~min}$ were included in the study group, and 30 healthy subjects were included in the control group. Low forced spitting unstimulated saliva was collected for five minutes in a test tube fitted with a funnel. Then electrode pads of the TENS unit were applied bilaterally on skin overlying the parotid glands and at optimal intensity, stimulated saliva was collected for 5 minutes with the same method in a separate graduated test tube. The salivary flow rate (per minute) was calculated by dividing the amount of collected saliva (volume in $\mathrm{mL}$ ) by the duration of collection period ( 5 minutes) and the salivary flow rates prior and after electrostimulation were compared for both groups. The Student's t-test (unpaired and paired) was performed for group-wise comparisons. Results: In study group, the mean unstimulated salivary flow rate was $0.07 \pm 0.01 \mathrm{~mL} / \mathrm{min}$. There was an $85.71 \%$ increase in salivary flow $(0.13 \pm 0.03$ $\mathrm{mL} / \mathrm{min})$ during the TENS application and the difference was highly significant $(\mathrm{p}<0.001)$. In control group, the mean unstimulated salivary flow rate was $0.37 \pm 0.07 \mathrm{~mL} / \mathrm{min}$. There was a $21.62 \%$ increase in salivary flow $(0.45 \pm 0.07 \mathrm{~mL} / \mathrm{min})$ during the TENS application and the difference was highly significant $(\mathrm{p}<0.001)$. An increase in mean salivary flow rate both in males and females after TENS application in both groups $(\mathrm{p}<0.001)$ was noted. The difference between unstimulated, stimulated and mean difference in salivary flow rate between males and females was not statistically significant in both groups ( $p>0.05)$. Conclusion: TENS can be an effective therapy in increasing whole salivary flow rates in patients with xerostomia.
\end{abstract}

Keywords: Saliva; Transcutaneous Electric Nerve Stimulation; Xerostomia. 


\section{Introduction}

In humans, the saliva is secreted by three pairs of major salivary glands, the parotid, the submandibular and the sublingual glands and in addition, 600-1,000 minor salivary glands line the oral and pharyngeal mucosa, which contributes a small portion of total salivary production [1,2].

Salivary gland hypofunction or hyposalivation is the condition of having reduced saliva production due to various causes, leading to the subjective complaint of oral dryness, which is termed xerostomia. It leads to numerous oral sequelae, including mucosal dryness, difficulty in mastication, deglutition and articulation, burning and pain of oral mucosa, propensity to damage of oral mucosa and recurrent infections, demineralization of teeth and increase in caries, dysgeusia, halitosis and difficulty to wear the dentures [3].

Palliative management of xerostomia includes topical agents such as ice chips and saliva substitutes, increasing water consumption, applying lip balm, chewing sugar-free gum, sucking sour lemon drops, paraffin and citric acid containing lozenges and rinses [4].

Electrostimulation to produce saliva was studied in the past and showed moderate promise but failed to become a component of mainstream therapy. However, results of recent preliminary investigations of noninvasive electronic stimulation of reflex salivation in xerostomic patients have been promising [5]. In addition, neural electrostimulation of salivary gland function by applying electric current, through the oral mucosa, on afferent nerve pathway receptors has been reported to increase saliva production and reduce the symptoms of xerostomia [6].

Research in this area is sparse and hence this study was undertaken to evaluate the effect of TENS therapy on whole salivary flow rate in patients with xerostomia.

\section{Material and Methods}

\section{Study Design and Sample}

This prospective clinical study was conducted in subjects of either sex in the age group of 25-70 years from outpatient department of Oral Medicine and Radiology, Chhattisgarh Dental College and Research Institute, Rajnandgaon, India.

Subjects $(\mathrm{n}=30)$ with a history of xerostomia (confirmed by mirror stick test) and subjects having unstimulated salivary flow equal to or less than $0.5 \mathrm{ml}$ in $5 \mathrm{~min}$ were included in the study group, and 30 healthy individuals were included in control group. Patients with pacemakers, defibrillator, hearing aid and cochlear implants, pregnancy and subjects with acute bacterial and viral sialadenitis were excluded from the study.

\section{Data Collection}

Subjects were asked to abstain from eating, drinking, chewing gum and oral hygiene procedures for 1 hour before the sample collection. Considering the diurnal variation in salivary flow, saliva was collected at around $11 \mathrm{am}$. All the subjects were made to sit in an upright position, with the head inclined forward and with minimal body and oro-facial movements. Patients were then asked to swallow saliva first and stay motionless, with 'low forced spitting' unstimulated saliva was collected for five minutes in a test tube fitted with a funnel. Collected saliva was measured using the micropipette and recorded.

Then electrode pads of the TENS unit (Vishal Medical Devices Pvt. Ltd., Hyderabad, India) were applied bilaterally on skin overlying the parotid glands with TENS unit in off position. The TENS unit was then activated and the intensity control switch was gradually increased and amplitude adjusted so that the 
patient did not have any discomfort. At this optimal intensity, stimulated saliva was collected for 5 min with the same method in a separate graduated test tube and flow rate was compared with unstimulated salivary flow rate. After procedure was completed, TENS unit was turned off, electrodes were removed, washed with water and mild soap gently and dried.

The salivary flow rate (per minute) was calculated by dividing the amount of collected saliva (volume in $\mathrm{mL}$ ) by the duration of collection period (five minutes) and the salivary flow rates prior and after electrostimulation were compared for both groups. Entire data obtained was entered in a master chart, tabulated and analyzed statistically. All the relevant data collected was entered in a proforma.

Statistical Analysis

The statistical analysis was done using the Statistical Package for Social Sciences (SPSS) version 22.0 for Windows (IBM Corp., Armonk, NY, USA). Student's t-test (unpaired and paired) was performed for groupwise comparisons. For all the tests, a p-value of 0.05 or less was considered statistically significant.

\section{Ethical Clearance}

Clearance was obtained from the Institutional Review Board (Protocol No. CDCRI/18/12). All the subjects were explained in detail in English/local language about the need and design of the study and their written consent was taken.

\section{Results}

The study group comprised 19 males and 11 females with a mean age of $52.1 \pm 11.6$ years (range 3070 years) and 15 males and 15 females with a mean age of $46.9 \pm 9.2$ years (range 25-59 years) in control group.

The mean unstimulated salivary flow rate was $0.07 \pm 0.01 \mathrm{~mL} / \mathrm{min}$. There was an $85.71 \%$ increase in salivary flow, i.e., $0.13 \pm 0.03 \mathrm{~mL} / \mathrm{min}$, during the TENS application and the difference was highly significant $(\mathrm{p}<0.001)$. The mean unstimulated salivary flow rate in males was $0.08 \pm 0.01 \mathrm{~mL} / \mathrm{min}$. There was a $75 \%$ increase in salivary flow (i.e., $0.14 \pm 0.04 \mathrm{~mL} / \mathrm{min}$ ) with the TENS application and the difference was statistically significant $(\mathrm{p}<0.001)$. In females, unstimulated salivary flow rate was $0.07 \pm 0.01 \mathrm{ml} / \mathrm{min}$. There was a $71.42 \%$ increase in salivary flow (i.e., $0.12 \pm 0.02 \mathrm{~mL} / \mathrm{min}$ ) with the application of TENS and the difference was statistically significant $(\mathrm{p}<0.001)$ (Table 1$)$.

Table 1. Comparison of unstimulated and stimulated salivary flow rate in study and control groups.

\begin{tabular}{|c|c|c|c|c|c|c|c|}
\hline \multirow[t]{2}{*}{ Groups } & \multirow[t]{2}{*}{ Particulars } & \multirow{2}{*}{$\begin{array}{l}\text { Unstimulated } \\
\text { (ml/min) }\end{array}$} & \multirow{2}{*}{$\begin{array}{c}\text { Stimulated } \\
(\mathrm{ml} / \mathrm{min})\end{array}$} & \multirow{2}{*}{$\begin{array}{l}\text { Mean Difference } \\
(\mathrm{ml} / \mathrm{min})\end{array}$} & \multirow[t]{2}{*}{ \% Difference } & \multicolumn{2}{|c|}{ Significance } \\
\hline & & & & & & $\mathbf{t}^{*}$ & p-value \\
\hline Study & $\mathrm{Mez}$ & $0.07 \pm 0.01$ & $0.13 \pm 0.03$ & 0.05 & $71.42 \%$ & 11.37 & $<0.001^{\#}$ \\
\hline Control & Mean \pm SD & $0.37 \pm 0.07$ & $0.45 \pm 0.07$ & $0.08 \pm 0.03$ & $21.62 \%$ & 13.59 & $<0.001^{\#}$ \\
\hline
\end{tabular}

t*: Paired ' $t$ ' test; \#: Highly significant.

In control group, the mean unstimulated salivary flow rate was $0.37 \pm 0.07 \mathrm{~mL} / \mathrm{min}$. There was a $21.62 \%$ increase in salivary flow, i.e., $0.45 \pm 0.07 \mathrm{~mL} / \mathrm{min}$ during the TENS application and the difference was highly significant $(\mathrm{p}<0.001)$. The mean unstimulated salivary flow rate in males was $0.38 \pm 0.07 \mathrm{~mL} / \mathrm{min}$. There was a $23.68 \%$ increase in salivary flow (i.e., $0.47 \pm 0.08 \mathrm{~mL} / \mathrm{min}$ ) with the TENS application and the difference was statistically significant $(\mathrm{p}<0.001)$. In females, unstimulated salivary flow rate was $0.36 \pm 0.06$ 
$\mathrm{ml} / \mathrm{min}$. There was a $19.44 \%$ increase in salivary flow (i.e., $0.07 \pm 0.01 \mathrm{~mL} / \mathrm{min}$ ) with the application of TENS and the difference was statistically significant $(\mathrm{p}<0.001)$ (Table 1). Statistical analysis of flow rates utilizing the unpaired ' $\mathrm{t}$ ' test for inter-group analysis demonstrated the difference between unstimulated, stimulated and mean difference in salivary flow rate between males and females was statistically not significant.

Statistical analysis of flow rates utilizing the unpaired ' $\mathrm{t}$ ' test for inter-group analysis demonstrated the difference between unstimulated, stimulated and mean difference in salivary flow rate between males and females was statistically not significant $(\mathrm{p}>0.001)$ (Table 2).

Table 2. Comparison of salivary flow rate between males and females in study group.

\begin{tabular}{|c|c|c|c|c|c|c|c|c|}
\hline \multirow[t]{2}{*}{ Groups } & \multirow[t]{2}{*}{ Gender } & \multirow{2}{*}{$\begin{array}{l}\text { No of } \\
\text { Cases }\end{array}$} & \multirow[t]{2}{*}{ Unstimulated } & \multirow[t]{2}{*}{ Stimulated } & \multirow{2}{*}{$\begin{array}{c}\text { Mean } \\
\text { Difference }\end{array}$} & \multirow[t]{2}{*}{ \% Difference } & \multicolumn{2}{|c|}{ Significance } \\
\hline & & & & & & & $t^{*}$ & p-value \\
\hline \multirow[t]{4}{*}{ Study } & Male & 19 & $0.08 \pm 0.01$ & $0.14 \pm 0.04$ & $0.06 \pm 0.03$ & $75 \%$ & 8.75 & $<0.001^{\#}$ \\
\hline & Female & 11 & $0.07 \pm 0.01$ & $0.12 \pm 0.02$ & $0.05 \pm 0.02$ & $71.42 \%$ & 8.15 & $<0.001^{\#}$ \\
\hline & Male vs. Female & $t^{* *}$ & 1.321 & 1.511 & & & & \\
\hline & & p-value & 0.557 & 0.052 & & & & \\
\hline \multirow[t]{4}{*}{ Control } & Male & 15 & $0.38 \pm 0.07$ & $0.47 \pm 0.08$ & $0.09 \pm 0.01$ & $23.68 \%$ & 12.13 & $<0.001^{\#}$ \\
\hline & Female & 15 & $0.36 \pm 0.06$ & $0.43 \pm 0.05$ & $0.07 \pm 0.01$ & $19.44 \%$ & 7.89 & $<0.001^{\#}$ \\
\hline & Male vs. Female & $t^{* *}$ & 0.832 & 1.423 & & & & \\
\hline & & p-value & 0.569 & 0.435 & & & & \\
\hline
\end{tabular}

t*: Paired 't' test; \#: Highly significant.

\section{Discussion}

Xerostomia is the subjective sensation of dry mouth, while hyposalivation is the objective finding of reduced salivary flow rate. Salivary secretion is normally controlled by reflex stimulation with effector nerve impulses conducting along sympathetic as well as parasympathetic nerves to the glands. Parasympathetic stimulation produces copious saliva of low protein concentration, whereas sympathetic stimulation produces little saliva but with high protein concentration, which may give a sensation of dryness [7,8].

Proponents of electrostimulation as a method to increase salivary production suggest that this procedure enhances the patient's ability to generate saliva by augmenting normal physiologic salivary reflexes $[4,5]$. In addition, TENS has been evaluated previously in stimulating salivary flow and found effective even in patients with xerostomia secondary to radiation therapy for head and neck cancer $[4,5,9,10]$.

In the present study, method unstimulated saliva collection was similar to Aagaard et al. [11], except a graduated tube was used in place of a preweighed cylinder and stimulated saliva collection was similar to Hargitai et al. [4]. The saliva was collected at an optimal intensity of TENS (the maximum intensity that the subject was comfortable).

In present study, whole saliva was collected instead of parotid saliva. Whole saliva measurements are simple to perform and are useful as an indicator of general salivary performance. They also provide meaningful information concerning quantitative aspects of gland function and can be obtained easily in dental office [12].

A wide range of unstimulated and stimulated salivary flow was observed in our study. In control group, there was a $21.62 \%$ increase in salivary flow during the TENS application and in study group there was an $85.71 \%$ increase in salivary flow, which was statistically significant. This variation of salivary flow rate was similar to the observation made by Mittal et al. [12], Pattipati et al. [13], and Vilas et al. [14].

Forty-eight out of fifty patients responded positively to TENS therapy. This result was in agreement with the study by Hargitai et al. [4] in which 15 (out of 22) healthy subjects demonstrated a significant increase in parotid salivary flow and the maximum increase was 8.75 fold greater than the baseline. Also, in a 
study by Domingo [15], six of the 18 patients demonstrated a significant increase in salivary flow after the TENS application.

In the present study, in two subjects, there was no increase in whole saliva flow. It could be attributed to patients' physical and mental status at the time of saliva collection. In a similar study carried out by Hargitai et al. [4], he had observed that TENS was unable to stimulate the parotid saliva. The authors proposed that TENS may act more efficiently as an accelerator of salivary flow rather than an initiator [4]. Therefore, TENS may likely be more effective in cases of decreased salivary gland function rather than an absolute absence of function.

In our study, the stimulated salivary flow rate was higher in males than females, but the difference in stimulated salivary flow between males and females was statically significant in the study group only. This may also be attributed to less number of female subjects in our study. Ghezzi et al. [16] showed no significant age and gender differences in salivary flow rates. In contrast, Vilas et al. [14] observed that the stimulated salivary flow rate was higher for males than for females.

The only adverse effect of TENS therapy seen in our study was mild twitching of the facial musculature, which was also described by Hargitai et al. [4]. However, the effect was minimal and transient and ceased immediately after the TENS unit switched off [4].

The mechanism by which the TENS unit acted on the parotid gland can be attributed to direct stimulation of the auriculotemporal nerve that supplies secretomotor drive to the parotid gland. It is believed that afferent nerves carry impulses from the periphery to the salivary nuclei (salivation center) in the medulla oblongata, which in turn directs signals to the efferent part of the reflex arch leading to initiation of salivation $[15]$.

The main advantage offered by TENS over other non-pharmacologic measures such as chewing gum or citric lozenges is that it is an extra-oral device with minimal side effects. It can be used while eating food and will not affect the normal mastication process $[17,18]$. Thus, the potential for salivary production while eating would be beneficial, which is not possible with an intraoral device. Chewing gum bases may need to be avoided in temporomandibular disorders and have had favorable but mixed results. Artificial saliva preparations can be used but have some limitations. The majority of commercial products available are based upon carboxymethylcellulose (CMC). However, these products do not contain specific antibacterial components, enzymes and other components of saliva. In addition, there are very few studies comparing currently available mouth wetting agents [4].

Similar to our study, Singh et al. [19] evaluated the effectiveness of TENS as a means of stimulating salivary function in healthy adult individuals and observed that 43 out of 50 participants demonstrated increased salivary flow when stimulated via the TENS unit. Vijayan et al. [20], Lakshman et al. [21], and Ojha et al. [22] determined the effectiveness of therapy TENS in stimulating salivary flow in patients who underwent radiation therapy for oral cancer. The authors observed an increase in the patients' salivary flow rate, and the treatment was well tolerated with no significant side effects [20-22].

As the results are encouraging, further multicenter studies with a larger sample size are required to evaluate the long-term clinical effectiveness of TENS in patients with xerostomia.

\section{Conclusion}

The present study substantiated that TENS can effectively increase whole salivary flow rates in patients with xerostomia. Thus, TENS as an extraoral device can be considered a safe, non-pharmacologic 
measure to increase the rate of unstimulated saliva. However, further studies should be conducted to evaluate the possibility of using TENS in relieving the symptoms of xerostomia.

\section{Authors' Contributions}

\begin{tabular}{|c|c|c|}
\hline $\mathrm{SC}$ & https://orcid.org/0000-0003-1614-8491 & Conceptualization and Data Curation. \\
\hline GKC & https://orcid.org/0000-0001-8091-8433 & Formal Analysis and Investigation. \\
\hline ASVP & https://orcid.org/o000-0002-2692-8822 & Methodology and Project Administration. \\
\hline LA & https://orcid.org/0000-0002-0280-434X & Data Curation and Writing - Review and Editing. \\
\hline SJ & https://orcid.org/0000-0003-4686-8713 & Data Curation and Writing - Review and Editing. \\
\hline SRP & (iD) https://orcid.org/0000-0003-0715-497X & Writing - Original Draft and Writing - Review and Editing. \\
\hline
\end{tabular}

\section{Financial Support}

None.

\section{Conflict of Interest}

The authors declare no conflicts of interest.

\section{Data Availability}

The data used to support the findings of this study can be made available upon request to the corresponding author.

\section{References}

[1] Kessler AT, Bhatt AA. Review of the major and minor salivary glands, part 1: anatomy, infectious, and inflammatory processes. J Clin Imaging Sci 2018; 8:47. https://doi.org/10.4103/jcis.JCIS_45_18

[2] Kessler AT, Bhatt AA. Review of the major and minor salivary glands, part 2: neoplasms and tumor-like lesions. J Clin Imaging Sci 2018; 8:48. https://doi.org/10.4103/jcis.JCIS_46_18

[3] Villa A, Connell CL, Abati S. Diagnosis and management of xerostomia and hyposalivation. Ther Clin Risk Manag 2014; 11:45-51. https://doi.org/10.2147/TCRM.S76282

[4] Hargitai IA, Sherman RG, Strother JM. The effects of electrostimulation on parotid saliva flow: a pilot study. Oral Surg Oral Med Oral Pathol Oral Radiol Endod 2005; 99(3):316-20. https://doi.org/10.1016/j.tripleo.2004.06.080

[5] Steller M, Chou L, Daniels TE. Electrical stimulation of salivary flow in patients with Sjögren's syndrome. J Dent Res 1988; 67(10):1334-7. https://doi.org/10.1177/00220345880670101701

[6] Strietzel FP, Martín-Granizo R, Fedele S, Lo Russo L, Mignogna M, Reichart PA, et al. Electrostimulating device in the management of xerostomia. Oral Dis 2007; 13(2):206-13. https://doi.org/10.1111/j.1601-0825.2006.01268.x

[7] Garrett JR. The proper role of nerves in salivary secretion: a review. J Dent Res 1987; 66(2):387-97. https://doi.org/10.1177/00220345870660020201

[8] Porter SR, Scully C, Hegarty AM. An update of the etiology and management of xerostomia. Oral Surg Oral Med Oral Pathol Oral Radiol Endod 2004; 97(1):28-46. https://doi.org/10.1016/j.tripleo.2003.07.010

[9] Travers MJ, O'Connell NE, Tugwell P, Eccleston C, Gibson W. Transcutaneous electrical nerve stimulation (TENS) for chronic pain: the opportunity to begin again. Cochrane Database Syst Rev 2020; 4:EDo00139. https://doi.org/10.1002/14651858.EDoo0139

[10] Wong RK, Jones GW, Sagar SM, Babjak AF, Whelan T. A Phase I-II study in the use of acupuncture-like transcutaneous nerve stimulation in the treatment of radiation-induced xerostomia in head-and-neck cancer patients treated with radical radiotherapy. Int J Radiat Oncol Biol Phys 2003; 57(2):472-80. https://doi.org/10.1016/s0360-3016(03)00572-8

[11] Aagaard A, Godiksen S, Teglers PT, Schiødt M, Glenert U. Comparison between new saliva stimulants in patients with dry mouth: a placebo-controlled double-blind crossover study. J Oral Pathol Med 1992; 21(8):376-80. https://doi.org/10.1111/j.1600-0714.1992.tb01369.x

[12] Mittal A, Masuria B L, Bajaj P. Transcutaneous electrical nerve stimulation in treatment of post herpetic neuralgia. Indian J Dermatol Venereol Leprol 1998; 64:45-7.

[13] Pattipati S, Patil R, Kannan N, Kumar BP, Shirisharani G, Mohammed RB. Effect of transcutaneous electrical nerve stimulation induced parotid stimulation on salivary flow. Contemp Clin Dent 2013; 4(4):427-31. https://doi.org/10.4103/0976-237X.123017

[14] Vilas SK, Shashikant M, Ali I. Evaluation of the effects of transcutaneous electrical nerve stimulation on whole saliva flow: A clinical study. J Ind Acad Oral Med Radiol 2009; 21(1):7-11. https://doi.org/10.4103/0972-1363.57771

[15] Domingo D. The effects of electrostimulation on saliva production in post-radiation head and neck cancer patients. Oral Surg Oral Med Oral Pathol Oral Radiol Endod 2004; 97(4):464. https://doi.org/10.1016/j.tripleo.2004.02.052 
[16] Ghezzi EM, Lange LA, Ship JA. Determination of variation of stimulated salivary flow rates. J Dent Res 2000; 79(11):1874-8. https://doi.org/10.1177/00220345000790111001

[17] Dyasnoor S, Kamath S, Khader NFA. Effectiveness of electrostimulation on whole salivary flow among patients with type 2 diabetes mellitus. Perm J 2017; 21:15-164. https://doi.org/10.7812/TPP/15-164

[18] Aparna PV, Sankari SL, Deivanayagi M, Priyadharshini A, Vishnupriya CK, Niveditha B. Effect of transcutaneous electrical nerve stimulation on parotid saliva flow in patients with hyposalivation. J Pharm Bioallied Sci 2017; 9(Suppl 1):S142-S146. https://doi.org/10.4103/jpbs.JPBS_124_17

[19] Singh D, Agrawal S, Shashikanth MC, Misra N. The effects of transcutaneous electric nerve stimulation (TENS) on salivary flow: a study. J Indian Acad Oral Med Radiol 2015; 27(1):16-9. https://doi.org/10.4103/0972-1363.167068

[20] Vijayan A, Asha ML, Babu S, Chakraborty S. Prospective phase II study of the efficacy of transcutaneous electrical nerve stimulation in post-radiation patients. Clin Oncol 2014; 26(12):743-7. https://doi.org/10.1016/j.clon.2014.09.00425262845

[21] Lakshman AR, Babu GS, Rao S. Evaluation of effect of transcutaneous electrical nerve stimulation on salivary flow rate in radiation induced xerostomia patients: a pilot study. J Cancer Res Ther 2015; 11(1):229-33. https://doi.org/10.4103/0973-1482.138008

[22] Ojha S, Bhovi TV, Jaju PP, Gupta M, Singh N, Shrivastava K. Effectiveness of transcutaneous electrical nerve stimulation on saliva production in post-radiated oral cancer patients. J Indian Acad Oral Med Radiol 2016; 28(3):246-5 1. https://doi.org/10.4103/0972-1363.195664 